\title{
Control of cellular redox status and upregulation of quinone reductase NQO1 via Nrf2 activation by $\alpha$-lipoic acid in human leukemia HL-60 cells
}

\author{
SELVAKUMAR ELANGOVAN and TZE-CHEN HSIEH \\ Department of Biochemistry and Molecular Biology, \\ New York Medical College, Valhalla, NY 10595, USA
}

Received May 15, 2008; Accepted June 27, 2008

DOI: 10.3892/ijo_00000071

\begin{abstract}
Lipoic acid (LA) is a naturally-occurring micronutrient that has been actively investigated for the treatment and management of various chronic medical conditions including neurodegenerative diseases, diabetes and hepatic disorders. However, relatively few studies have examined the effects of LA as a chemopreventive agent, particularly in regard to its ability to modulate homeostasis of oxidoreductive state and to regulate detoxification enzymes such as quinone reductase NQO1 in LA-responsive cells. We tested the hypothesis that LA affects the intracellular redox status and induces NQO1 expression using the human promyelocytic HL-60 leukemia cells. We showed that treatment by LA maintains HL-60 cells in a relatively reduced state, supported by the dose/time-dependent increase in the activities of glutathione peroxidase and glutathione reductase and decrease in the activity of catalase. Moreover, LA significantly increased the activity and protein expression of NQO1. The induction of NQO1 was accompanied by the nuclear accumulation of transcription factor Nrf2, which was correlated with a decreased level of Nrf2 in the cytosol as well as the concomitant reduction in the expression of cytoplasmic repressor of Nrf2, Keap1.
\end{abstract}

\section{Introduction}

Cancer chemoprevention has been defined as a strategy for reducing cancer mortality by the prevention, delay or reversal of carcinogenesis by the administration of dietary or pharmaceutical agents. The upregulation of cellular defense genes, such as phase II detoxification enzymes and stress response proteins, is believed to play an important biological function in

Correspondence to: Dr Tze-chen Hsieh, Room 133, Department of Biochemistry and Molecular Biology, Basic Sciences Building, New York Medical College, Valhalla, NY 10595, USA

E-mail: tze-chen_hsieh@nymc.edu

Key words: $\alpha$-lipoic acid, intracellular redox status, induction of quinone oxidoreductase-1, Nrf2, Kelch-like ECH-associated protein 1 the protection against carcinogenesis and in the attenuation of cancer development, by counteracting against the deleterious potential of reactive carcinogenic metabolites and reactive oxygen species (1). The phase II enzymes, including $\mathrm{NAD}(\mathrm{P}) \mathrm{H}$ :quinone oxidoreductase-1 (NQO1) and glutathioneS-transferase (GST), can convert electrophiles (ultimate carcinogens) to less reactive compounds, which can in turn conjugate to sugars, glutathione and sulfates resulting in less toxic and more excretable compounds (2). Central to the phase II gene response is the Nrf2-Keap1 transcription system, which appears to be the primary molecular target of chemopreventive agents (3). Under basal condition, Nrf2 is tethered to a cytoplasmic repressor protein, Kelch-like ECHassociated protein 1 (Keap1). Oxidative or chemical stresses, however, are 'sensed' by Keap1, resulting in a disruption of Nrf2/Keap1 complex and facilitating the translocation of Nrf2 into the nucleus, where it induces the transcription of phase II detoxifying genes by binding to antioxidant responsive element ARE sequences $(4,5)$. Identification and characterization of new chemopreventive agents that control these epigenetic changes will clearly offer new opportunities for the prevention of cancer, and in recent years, cancer prevention by natural products has received considerable attention $(6,7)$.

$\alpha$-Lipoic acid (LA) is a micronutrient with diverse biological and pharmacological properties. It occurs naturally in trace amounts in mammalian cells such as lipoamide, an essential cofactor in pyruvate dehydrogenase and $\alpha$-ketoglutarate dehydrogenase complexes and plays a fundamental role in oxidative metabolism (8). Several features have been described for LA such as i) free radical scavenging, ii) interaction with other antioxidants, iii) metalchelation, iv) modulation of gene expression and v) repair of oxidative damage (9-11). When added to a cell culture medium in vitro, LA readily enters cells and is reduced and rapidly effluxed from the cell to the culture medium (12). LA has been utilized in the treatment of various chronic diseases such as diabetes, liver and neurogenerative disorders (13).

In recent years, LA has gained some attention in the field of cancer as an anticancer agent $(14,15)$. Cell-based studies have suggested that the tumor-suppressive effect of LA corresponds with induction of apoptosis and this induction is selectively exerted in cancer and transformed cell lines, while being less active toward normal nontransformed cells (16-19). 
Moreover, LA has also been shown to induce several phase II genes (20-22).

Details of the effect of LA in chemoprevention remain ill-defined. Therefore, studies investigating the role of LA in the induction of cancer preventive genes and the elucidation of detailed upstream signaling mechanisms related to the Nrf2-Keap1 system may help to identify new molecular mechanisms and targets of the cancer protective effects of LA. In this study, we tested the hypothesis that LA may induce the expression of phase II detoxification genes such as NQO1 by activating the Nrf2/Keap1 pathway in HL-60 cells . Specifically, we evaluated i) the effect of LA on modulation of oxidative stress, ii) NQO1 induction by LA treatment and iii) the subcellular localization and translocation of $\mathrm{Nrf} 2$.

\section{Materials and methods}

DL- $\alpha$-Lipoic acid was purchased from LKT laboratories (St. Paul, MN). BSA, GSH, oxidized glutathione, menadione, dicoumarol, NADPH and glutathione reductase were purchased from Sigma Chemicals (St. Louis, MO). Primary antibodies such as mouse monoclonal anti-NQO1, goat polyclonal anti-Keap1, rabbit polyclonal anti-Nrf2, mouse monoclonal anti-actin, mouse monoclonal anti-histone $\mathrm{H} 1$ and secondary antibodies were purchased from Santa Cruz Biotechnology, Inc (Santa Cruz, CA). Fetal calf serum, RPMI-1640, penicillin and streptomycin were purchased from Cellgro, Inc (Herndon, VA). All other chemicals and solvents used were of analytical grade.

Cell culture, growth inhibition assay, colony formation assay and cell morphology. Human HL-60 cells were supplied by American Tissue Culture Collection (Manassas, VA) and maintained in RPMI-1640 supplemented with penicillin, streptomycin and $10 \%$ heat inactivated fetal calf serum, as previously described $(23,24)$. For treatment, cells were seeded at a density of $1 \times 10^{5}$ cells $/ \mathrm{ml}$. DL- $\alpha$-Lipoic acid dissolved in $1 \mathrm{~N} \mathrm{NaOH}$ solution and neutralized with $\mathrm{HCl}$, was added to the culture media to the final concentration specified in the text.

Preparation of cell extracts for immunoblot analysis and enzyme activity assay. For immunoblotting experiments, cells were collected by centrifugation and were lysed in ice-cold RIPA buffer (50 mM Tris, pH 7.4, $150 \mathrm{mM} \mathrm{NaCl}, 1 \mathrm{mM}$ EDTA, $1 \%$ Triton X-100, $1 \%$ deoxycholate, $0.1 \%$ SDS, $1 \mathrm{mM}$ dithiothreitol and $10 \mu \mathrm{l} / \mathrm{ml}$ protease inhibitor cocktail). To measure the activities of enzymes, control and treated cells were collected by centrifugation and resuspended in ice-cold $50 \mathrm{mM}$ potassium phosphate buffer ( $\mathrm{pH}$ 7.4) containing $2 \mathrm{mM}$ EDTA. The cells were sonicated, followed by centrifugation at $13,000 \mathrm{x} \mathrm{g}$ for $10 \mathrm{~min}$ at $4^{\circ} \mathrm{C}$. The resulting supernatants were collected for the immediate measurement of various enzyme activities. Nuclear fractions for the analysis of Nrf2 translocation were isolated using a commercially available kit (Sigma Chemicals). Protein content of cell lysates and nuclear extracts were determined by Coomassie protein assay kit (Pierce, Rockford, IL) with BSA as standard.

Immunoblotting. The aliquots of lysates (20 $\mu \mathrm{g}$ of protein) were boiled with sample buffer for $5 \mathrm{~min}$ and resolved by
$10 \%$ SDS-PAGE. The proteins were transferred to a nitrocellulose membrane and blocked in TBST buffer $(10 \mathrm{mM}$

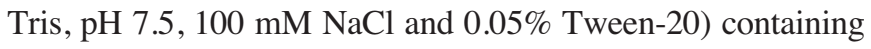
$3 \%$ nonfat dried milk overnight at $4{ }^{\circ} \mathrm{C}$. The blots were incubated with primary antibodies (anti-NQO1, anti-Nrf2, anti-Keap1, anti-histone and anti-actin), followed by incubation for $1 \mathrm{~h}$ with appropriate secondary antibodies conjugated to horseradish peroxidase in TBST. Actin and histone expression was used as loading control. The intensity of the specific immunoreactive bands were detected by ECL, quantified by densitometry and expressed as a ratio to actin or histone, as previously described (23).

Assay of quinone reductase 1 (NQO1) activity. Activity of NQO1 was assayed as previously described (25), with slight modifications. Briefly, the reaction mixture contained $33 \mathrm{mM}$ potassium phosphate buffer ( $\mathrm{pH} 7.4), 0.18 \mathrm{mM}$ NADPH, $20 \mu \mathrm{M}$ menadione, $0.02 \%$ bovine serum albumin, $0.01 \%$ Tween-20 and cell lysates. The reaction was started by the addition of menadione and the oxidation of NADPH was followed spectrophotometrically at $340 \mathrm{~nm}$ for $2 \mathrm{~min}$. Assays were performed at $25^{\circ} \mathrm{C}$ with and without $20 \mu \mathrm{M}$ dicoumarol. The dicoumarol-sensitive part of the activity was taken as a measure of the NQO1 activity, which was expressed as $\mu \mathrm{mol}$ of NADPH oxidized $/ \mathrm{min} / \mathrm{mg}$ protein using the extinction coefficient $\left(6.22 \mathrm{mM}^{-1} \mathrm{~cm}^{-1}\right)$.

Assay of superoxide dismutase (SOD). SOD activity was assayed using a commercially available kit (Fluka, Switzerland).

Assay of catalase. Catalase was assayed, as previously described (26). Briefly, $0.5 \mathrm{ml}$ of potassium phosphate buffer $(\mathrm{pH} 7.0)$ and $50 \mu \mathrm{l}$ of cell lysates were added to a quartz cuvette. The reaction was started by adding $20 \mu \mathrm{l}$ of $\mathrm{H}_{2} \mathrm{O}_{2}$ and the decomposition of $\mathrm{H}_{2} \mathrm{O}_{2}$ was monitored at $25^{\circ} \mathrm{C}$ for $1 \mathrm{~min}$. The activity of catalase was calculated using extinction coefficient $\left(0.0436 \mathrm{mM}^{-1} \mathrm{~cm}^{-1}\right)$ and expressed as $\mu \mathrm{mol}$ of $\mathrm{H}_{2} \mathrm{O}_{2}$ decomposed $/ \mathrm{min} / \mathrm{mg}$ protein.

Assay of glutathione peroxidase (GPx) activity. Cellular GPx activity was measured by the method of Flohe and Gunzler (27) and expressed as $\mu \mathrm{mol}$ of NADPH oxidized $/ \mathrm{min} / \mathrm{mg}$ protein.

Assay of glutathione reductase (GR). GR was assayed by the method of Worthington and Rosemeyer (28) by following the change in absorbance due to oxidation of NADPH. GR activity was expressed as U/mg protein.

Statistical analysis. The results were expressed as mean \pm standard deviation (SD). Differences between groups were assessed by one-way analysis of variance using the SPSS software package for Windows. Statistical significance for inter-group comparisons at $\mathrm{P}$-values $<0.001,<0.01$ and $<0.05$ is provided in the figures.

\section{Results}

LA alters cellular redox status. Oxidative stress has been implicated in different aspects of cancer, from carcinogenesis 
(A) SOD

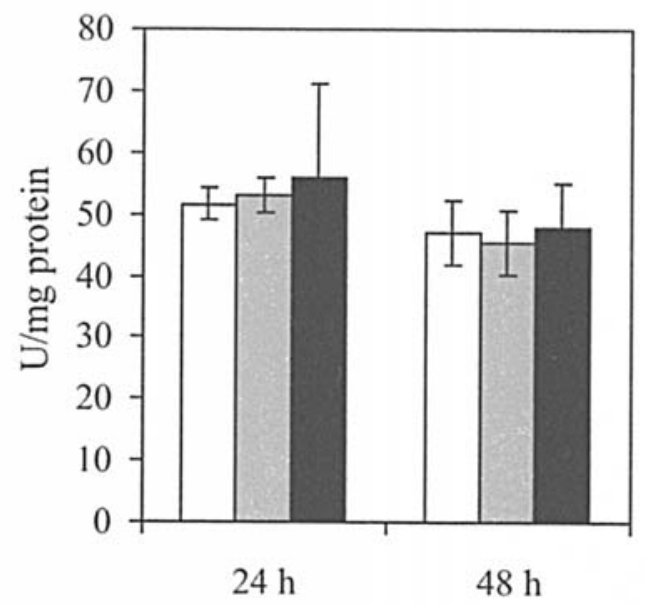

(C) GPX

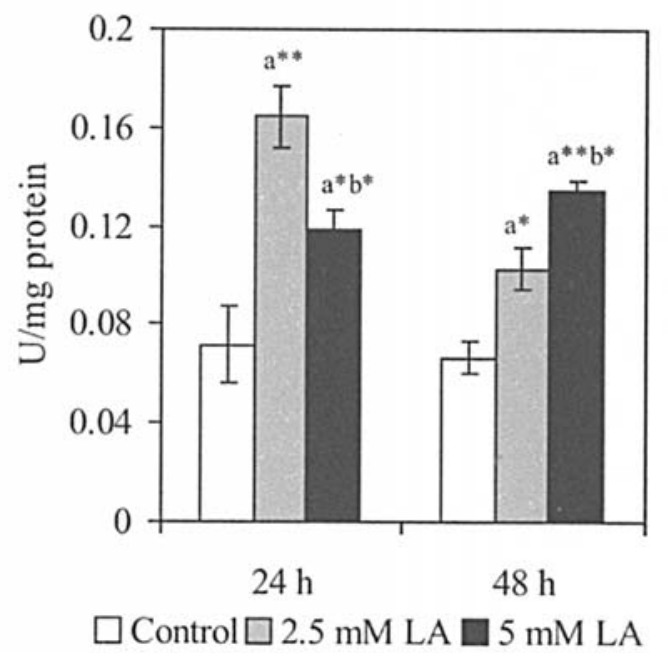

(B) Catalase

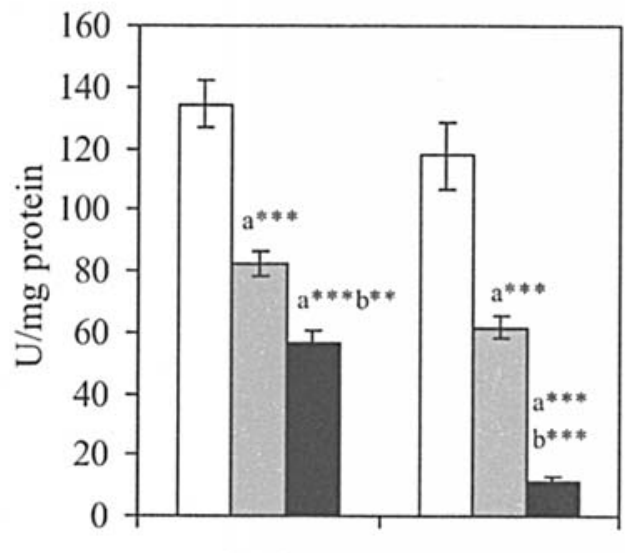

$24 \mathrm{~h}$

$48 \mathrm{~h}$

(D) GR

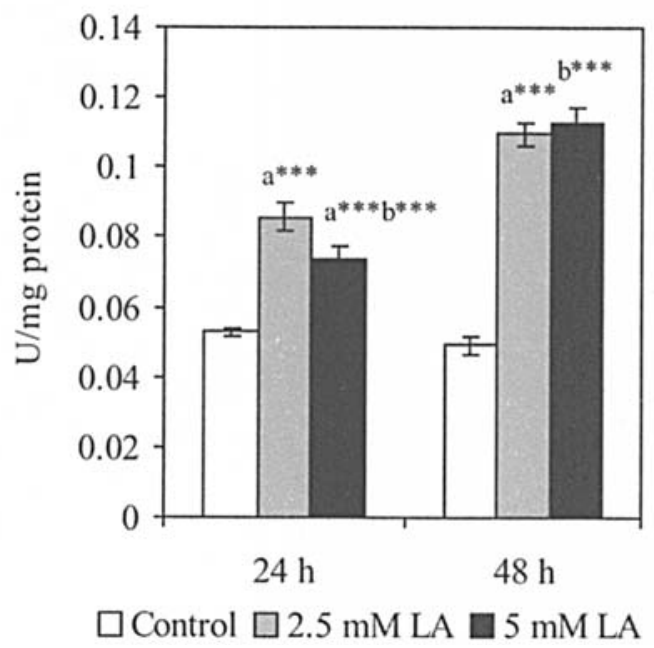

Figure 1. LA-induced alterations on the activities of antioxidant enzymes. HL-60 cells were incubated with the indicated concentrations of LA and the activities of antioxidant enzymes (A) SOD, (B) catalase, (C) GPx and (D) GR were measured as described in Materials and methods. Values are mean \pm SD for three experiments. Comparisons are made between: a, control and $2.5 \mathrm{mM}, 5 \mathrm{mM}$ LA-treated groups; b, $2.5 \mathrm{mM}$ LA and $5 \mathrm{mM}$ LA-treated groups. The symbols represent statistical significance: ${ }^{*} \mathrm{P}<0.05,{ }^{* *} \mathrm{P}<0.01$ and ${ }^{* * *} \mathrm{P}<0.001$.

to treatment and prevention. For example, the frequency of gene mutations is likely to be increased under conditions when oxidative stress largely exceeds the oxidation-reduction capacity of the body. The ability of LA to counteract oxidative stress in both aqueous and lipophilic intracellular environments prompted an investigation of treatment by LA in affecting the intracellular redox status. Results in Fig. 1 show that treatment by LA favors the maintenance of a reductive intracellular state as evidenced by the altered activity of antioxidant enzymes (Fig. 1A-D). Incubation of HL-60 cells, which have been widely used in chemoprevention studies $(29,30)$ with LA for 24 and $48 \mathrm{~h}$ resulted in a significant induction of cellular GPX and GR in a dose- and time-dependent manner; whereas the activity of SOD was not significantly altered by LA. In contrast to other antioxidant enzymes, the activity of catalase was significantly decreased by LA treatment in a dose- and time-dependent manner.

LA induces NQO1 expression. An equally important cellular defensive mechanism against oxidative stress involves phase II detoxification enzymes such as quinone reductase (NQO1), which reduces the reactive products of phase I metabolic reactions. Accordingly, we determined the influence of LA on changes in the activity and levels of NQO1. As shown in Fig. 2A, incubation of HL-60 cells with 2.5 and $5 \mathrm{mM}$ LA for up to $48 \mathrm{~h}$ resulted in a significant increase in NQO1 activity. To determine whether an increase in NQO1 activity resulted from changes in its expression, Western blotting studies were performed by using whole cell lysates (Fig. 2B). In agreement with the results of the enzyme activity determinations, LA treatment resulted in a dose- and time-dependent increase in NQO1 protein expression as compared with the control.

LA enhances nuclear translocation of Nrf2 while reducing Keapl protein level. Nrf2 is a major transcription factor involved in cellular protection against oxidative stress through ARE-mediated induction of several phase II detoxification and antioxidant enzymes $(4,5)$. Therefore, the next question we asked was whether the activation of NQO1 is due to the changes in the localization of Nrf2 in HL-60 cells. As shown in Fig. 3A, LA treatment significantly enhanced the nuclear accumulation of Nrf2 in a dose- and time-dependent manner 
(A)

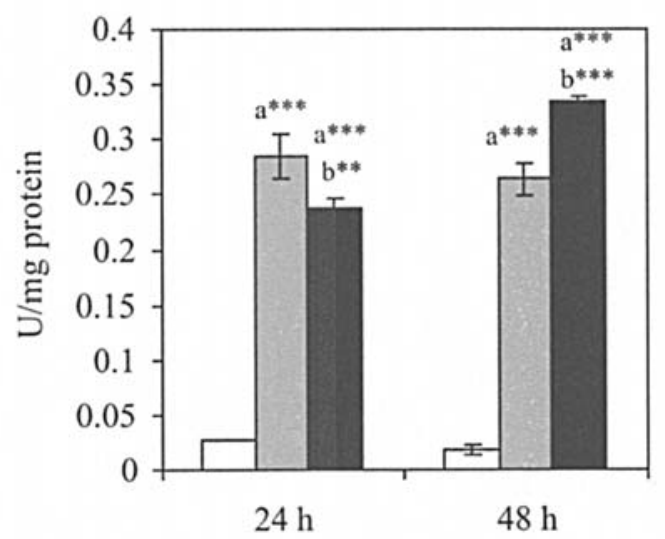

(B)

$\square$ Control $\square 2.5$ mM LA $\square 5$ mM LA

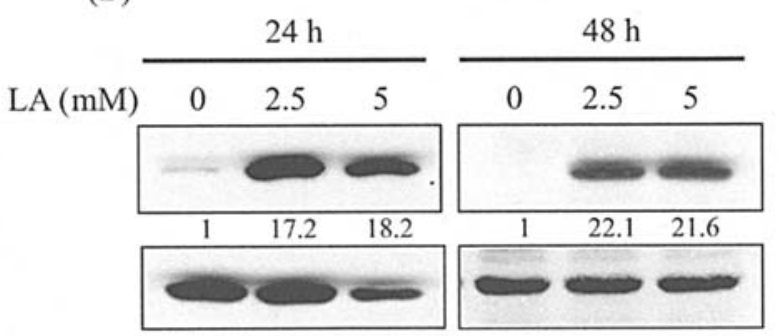

NQO1

Figure 2. Induction of NQO1 by LA. (A) HL-60 cells were treated with varying concentrations of LA (0-5 mM) for 24 and $48 \mathrm{~h}$ and the cells were analyzed for changes in NQO1 activity. Values are expressed as mean \pm SD for three experiments. Unit: $\mu \mathrm{mol}$ of NADPH oxidized $/ \mathrm{min} / \mathrm{mg}$ protein. Comparisons are made between: a, control and $2.5 \mathrm{mM}, 5 \mathrm{mM}$ LA-treated groups; b, $2.5 \mathrm{mM} \mathrm{LA}$ and $5 \mathrm{mM}$ LA-treated groups. The symbols represent statistical significance: ${ }^{*} \mathrm{P}<0.05,{ }^{* *} \mathrm{P}<0.01$ and ${ }^{* * *} \mathrm{P}<0.001$. (B). Effect of LA on NQO1 protein levels was determined by Western blot analysis, as detailed in Materials and methods.

and obtained greatest induction at $5 \mathrm{mM}$ for $24 \mathrm{~h}$. There was no increase of Nrf2 expression with $5 \mathrm{mM}$ LA at $48 \mathrm{~h}$, likely due to the toxic effects and loss of cell viability at this high dose level. In contrast, LA reduced the level of Keap1 under the same treatment conditions (Fig. 3B). These results suggest that LA may stimulate Nrf2-mediated ARE activation by enhancing nuclear Nrf2 protein level and reducing Keap1 at the same time, by increasing the ratio of Nrf2/Keap1 .

\section{Discussion}

LA has pleiotropic pharmacological effects. The therapeutic potential of LA in cancer treatment has been shown in several studies $(14,18,19)$. However, whether the cancer chemopreventive properties of LA involve changes in Nrf2 and antioxidant gene expression has not been reported. Using HL-60 cells, we provide evidence for three novel observations regarding cancer chemopreventive potential for LA: i) LA alters the redox status of treated cells, ii) LA induces the expression of NQO1 and iii) LA activates the Nrf2 pathway, increasing Nrf2 nuclear translocation accompanied by a reduction in the Keap1 level.

The results of this study clearly demonstrated that the basal levels of antioxidant enzymes such as GPx and GR were
(A)
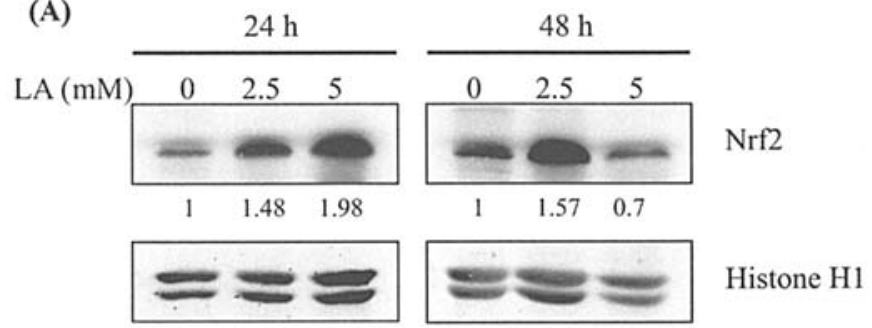

(B)
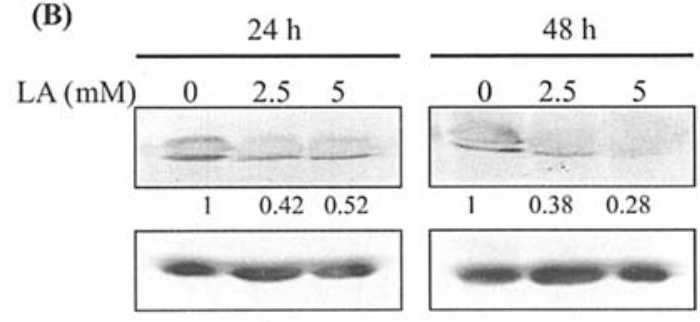

Keap1

Actin

Figure 3. LA induces nuclear Nrf2 and decreases cytosolic Keap-1 levels. (A) The time- and dose-dependent changes in nuclear Nrf2 levels by LA were determined by Western blot analysis. Histone $\mathrm{H} 1$ was used as a loading control to confirm increases in nuclear Nrf2 expression by LA. (B) Western blot analysis of Keap1 protein levels in cell lysates. Actin was used as a loading control.

increased after LA treatment. In contrast, the activity of catalase was significantly lowered by LA treatment. GPx and catalase are two critical cellular defenses involved in the decomposition of $\mathrm{H}_{2} \mathrm{O}_{2}$ (31) and the LA-induced alterations in this finely balanced antioxidant system may indicate that the change in redox balance is also one of the driving forces for the induction of cytoprotective genes. The decreased activity of catalase also supports the pro-oxidant role of LA, which is generally observed under non-oxidative stress conditions (18). Furthermore, the induction of GR by LA may lead to increased regeneration of GSH from GSSG produced during GPx-catalyzed decomposition of $\mathrm{H}_{2} \mathrm{O}_{2}$. The basal level of SOD was not altered by LA treatment, suggesting that LA was not involved in the regulation of SOD expression in HL-60 cells.

The present study also indicated that LA induced nearly 10 -fold increase in NQO1 activity and 20-fold increase in Nrf2 protein expression in HL-60 cells. The significant induction of NQO1 by LA suggests a novel mechanism through which LA may contribute to the cancer chemoprevention. NQO1 is a main phase II detoxification enzyme that catalyzes the two-electron reductions of a variety of quinone compounds and, thereby, protects cells against mutagenicity and carcinogenicity resulting from free radicals and toxic oxygen metabolites generated by the one-election reductions promoted by cytochrome $\mathrm{P} 450$ and other enzymes (32). Therefore, the induction of NQO1 by LA would provide protection against carcinogenicity, mutagenicity and other toxicities caused by carcinogenic xenobiotics.

Another significant finding in this study is the demonstration of the involvement of the Nrf2 pathway in LA-mediated NQO1 induction. A number of recent studies have demonstrated that Nrf2 is a critical transcription factor in regulating the expression of a variety of cytoprotective 
genes encoding for antioxidative enzymes and phase II genes in various types of cells/tissues (5,33-35). Under basal conditions, Nrf2 is sequestered in the cytoplasm by actinbinding protein Keap1 and rapidly (half-life is $<20 \mathrm{~min}$ ) undergoes ubiquitin-mediated proteasomal degradation assisted by Keap1 as an adaptor for Cul3-based E3 ligase (36). Keap1 has abundant free cysteine residues (25 cysteines), which makes it an ideal redox-sensing partner (37). When cells are exposed to chemopreventive agents and oxidative stress, a signal involving phosphorylation and/or redox modification is transmitted to the Nrf2/Keap1 complex, leading to dissociation of Keap1 resulting in the subsequent nuclear translocation of Nrf2 (5). In the nucleus, Nrf2 forms a heterodimer with small-Maf protein and activates the transcription of oxidative stress-related proteins via ARE (38). In this study, LA decreased the level of Keap1 and increased the nuclear accumulation of $\mathrm{Nrf} 2$ and this rapid accumulation may result in increased binding activity of Nrf2 to ARE and presumably serves to enhance the expression of various phase II and antioxidative enzymes.

Details of activation of the Nrf2/Keap1 complex upon exposure to LA remain to be elucidated. Conceivably, the post-translational modification (phosphorylation) of either of these proteins by various protein kinase signaling pathways may be involved (6). Induction of the Nrf2/Keap1 system by LA may be also partly due to LA-induced redox imbalance as evidenced from the decreased activity of catalase observed in this study. It is of interest to note that McCarty (39) describes LA as apparently an ideal agent for catalyzing and/or promoting disulfide bond formation in proteins, since LA and its vicinal dithiol form, optimally fits the requirements for induction of a protective "phase II response'. Its ability in this regard is illustrated by its impact on the transcriptional activities of nuclear factor $\kappa \mathrm{B}(\mathrm{NF} \kappa \mathrm{B})$ and activator protein 1 (AP-1) $(40,41)$. Experiments designed to test the above hypothesis are underway in our laboratory.

A point of interest to consider is the concentration of LA used in this exploratory study. These concentrations were similar to those used in other in vitro studies, in which LA has been reported to induce cell cycle arrest and apoptosis (17). In addition, plasma levels of LA in the millimolar range after oral dosing have been safely reached in pharmacokinetic studies. However, the half-life of LA in plasma is short (30 min), suggesting that it is rapidly taken up into tissues or metabolized (42) and it is therefore plausible that higher concentrations may accumulate in target tissues.

In conclusion, the results of this study demonstrate conclusively that LA treatment shows the release of Nrf2 from Keap1 with the subsequent translocation into the nucleus, and the induction of the various cytoprotective genes including NQO1. Activation of this Nrf2 signaling pathway would likely contribute to the beneficial effects of this readily available dietary supplement, which could help to fight various cancers.

\section{Acknowledgements}

We thank Dr Joseph M. Wu for helpful suggestions relating to this study.

\section{References}

1. Kong AN, Yu R, Hebbar V, Chen C, Owuor E, Hu R, Ee R and Mandlekar S: Signal transduction events elicited by cancer prevention compounds. Mutat Res 480-481: 231-241, 2001.

2. Kwak MK, Wakabayashi N and Kensler TW: Chemoprevention through the Keap1-Nrf2 signaling pathway by phase 2 enzyme inducers. Mutat Res 555: 133-148, 2004.

3. Yu X and Kensler T: Nrf2 as a target for cancer chemoprevention. Mutat Res 591: 93-102, 2005.

4. Shen G, Jeong WS, Hu R and Kong AN: Regulation of Nrf2, NF-kappaB, and AP-1 signaling pathways by chemopreventive agents. Antioxid Redox Signal 7: 1648-1663, 2005.

5. Giudice A and Montella M: Activation of the Nrf2-ARE signaling pathway: a promising strategy in cancer prevention. Bioessays 28: 169-181, 2006.

6. Jeong WS, Jun M and Kong AN: Nrf2: a potential molecular target for cancer chemoprevention by natural compounds. Antioxid Redox Signal 8: 99-106, 2006.

7. Thomasset SC, Berry DP, Garcea G, Marczylo T, Steward WP and Gescher AJ: Dietary polyphenolic phytochemicals - promising cancer chemopreventive agents in humans? A review of their clinical properties. Int J Cancer 120: 451-458, 2007.

8. Bast $\mathrm{A}$ and Haenen GR: Lipoic acid: a multifunctional antioxidant. Biofactors 17: 207-213, 2003.

9. Packer L, Witt EH and Tritschler HJ: alpha-Lipoic acid as a biological antioxidant. Free Radic Biol Med 19: 227-250, 1995.

10. Packer L, Tritschler HJ and Wessel K: Neuroprotection by the metabolic antioxidant alpha-lipoic acid. Free Radic Biol Med 22: 359-378, 1997.

11. Packer L, Kraemer K and Rimbach G: Molecular aspects of lipoic acid in the prevention of diabetes complications. Nutrition 17: 888-895, 2001.

12. Jones W, Li X, Qu ZC, Perriott L, Whitesell RR and May JM: Uptake, recycling, and antioxidant actions of alpha-lipoic acid in endothelial cells. Free Radic Biol Med 33: 83-93, 2002.

13. Bilska A and Wlodek L: Lipoic acid - the drug of the future? Pharmacol Rep 57: 570-577, 2005.

14. Simbula G, Columbano A, Ledda-Columbano GM, Sanna L, Deidda M, Diana A and Pibiri M: Increased ROS generation and p53 activation in alpha-lipoic acid-induced apoptosis of hepatoma cells. Apoptosis 12: 113-123, 2007.

15. Vig-Varga E, Benson EA, Limbil TL, Allison BM, Goebl MG and Harrington MA: Alpha-lipoic acid modulates ovarian surface epithelial cell growth. Gynecol Oncol 103: 45-52, 2006.

16. Pack RA, Hardy K, Madigan MC and Hunt NH: Differential effects of the antioxidant alpha-lipoic acid on the proliferation of mitogen-stimulated peripheral blood lymphocytes and leukaemic T cells. Mol Immunol 38: 733-745, 2002.

17. van de Mark K, Chen JS, Steliou K, Perrine SP and Faller DV: Alpha-lipoic acid induces p27Kip-dependent cell cycle arrest in non-transformed cell lines and apoptosis in tumor cell lines. J Cell Physiol 194: 325-340, 2003.

18. Wenzel U, Nickel A and Daniel H: alpha-Lipoic acid induces apoptosis in human colon cancer cells by increasing mitochondrial respiration with a concomitant O2-"-generation. Apoptosis 10: 359-368, 2005.

19. Moungjaroen J, Nimmannit U, Callery PS, Wang L, Azad N, Lipipun V, Chanvorachote P and Rojanasakul Y: Reactive oxygen species mediate caspase activation and apoptosis induced by lipoic acid in human lung epithelial cancer cells through Bcl-2 down-regulation. J Pharmacol Exp Ther 319: 1062-1069, 2006.

20. Flier J, Van Muiswinkel FL, Jongenelen CA and Drukarch B: The neuroprotective antioxidant alpha-lipoic acid induces detoxication enzymes in cultured astroglial cells. Free Radic Res 36: 695-699, 2002.

21. Cao Z, Tsang M, Zhao H and Li Y: Induction of endogenous antioxidants and phase 2 enzymes by alpha-lipoic acid in rat cardiac $\mathrm{H} 9 \mathrm{C} 2$ cells: protection against oxidative injury. Biochem Biophys Res Commun 310: 979-985, 2003.

22. Ogborne RM, Rushworth SA and O'Connell MA: Alpha-lipoic acid-induced heme oxygenase- 1 expression is mediated by nuclear factor erythroid 2-related factor 2 and p38 mitogenactivated protein kinase in human monocytic cells. Arterioscler Thromb Vasc Biol 25: 2100-2105, 2005.

23. DiPietrantonio AM, Hsieh TC, Olson SC and Wu JM: Regulation of G1/S transition and induction of apoptosis in HL-60 leukemia cells by fenretinide (4HPR). Int J Cancer 78: 53-61, 1998. 
24. Hsieh TC, Kunicki J, Darzynkiewicz Z and Wu JM: Effects of extracts of Coriolus versicolor (I'm-Yunity) on cell-cycle progression and expression of interleukins- 1 beta, -6 , and -8 in promyelocytic HL-60 leukemic cells and mitogenically stimulated and nonstimulated human lymphocytes. J Altern Complement Med 8: 591-602, 2002.

25. Lind C, Cadenas E, Hochstein P and Ernster L: DT-diaphorase: purification, properties, and function. Methods Enzymol 186: 287-301, 1990.

26. Aebi H: Catalase in vitro. Methods Enzymol 105: 121-126, 1984.

27. Flohe L and Gunzler WA: Assays of glutathione peroxidase. Methods Enzymol 105: 114-121, 1984.

28. Worthington DJ and Rosemeyer MA: Glutathione reductase from human erythrocytes. Catalytic properties and aggregation. Eur J Biochem 67: 231-238, 1976.

29. Suh N, Luyengi L, Fong HH, Kinghorn AD and Pezzuto JM: Discovery of natural product chemopreventive agents utilizing HL-60 cell differentiation as a model. Anticancer Res 15: 233-239, 1995.

30. Jang M, Cai L, Udeani GO, Slowing KV, Thomas CF, Beecher CW, Fong HH, Farnsworth NR, Kinghorn AD, Mehta RG, Moon RC and Pezzuto JM: Cancer chemopreventive activity of resveratrol, a natural product derived from grapes. Science 275: 218-220, 1997.

31. Veal EA, Day AM and Morgan BA: Hydrogen peroxide sensing and signaling. Mol Cell 26: 1-14, 2007.

32. Cuendet M, Oteham CP, Moon RC and Pezzuto JM: Quinone reductase induction as a biomarker for cancer chemoprevention. J Nat Prod 69: 460-463, 2006.

33. Kohle C and Bock KW: Coordinate regulation of Phase I and II xenobiotic metabolisms by the Ah receptor and Nrf2. Biochem Pharmacol 73: 1853-1862, 2007.

34. Kraft AD, Lee JM, Johnson DA, Kan YW and Johnson JA: Neuronal sensitivity to kainic acid is dependent on the Nrf2mediated actions of the antioxidant response element. J Neurochem 98: 1852-1865, 2006.
35. Hu R, Xu C, Shen G, Jain MR, Khor TO, Gopalkrishnan A, Lin W, Reddy B, Chan JY and Kong AN: Identification of Nrf2-regulated genes induced by chemopreventive isothiocyanate PEITC by oligonucleotide microarray. Life Sci 79: 1944-1955, 2006.

36. Itoh $\mathrm{K}$, Wakabayashi $\mathrm{N}$, Katoh $\mathrm{Y}$, Ishii T, O'Connor $\mathrm{T}$ and Yamamoto M: Keap 1 regulates both cytoplasmic-nuclear shuttling and degradation of Nrf2 in response to electrophiles. Genes Cells 8: 379-391, 2003.

37. Dinkova-Kostova AT, Holtzclaw WD, Cole RN, Itoh K, Wakabayashi N, Katoh Y, Yamamoto M and Talalay P: Direct evidence that sulfhydryl groups of Keap1 are the sensors regulating induction of phase 2 enzymes that protect against carcinogens and oxidants. Proc Natl Acad Sci USA 99: 11908-11913, 2002.

38. Hong F, Sekhar KR, Freeman ML and Liebler DC: Specific patterns of electrophile adduction trigger Keap1 ubiquitination and Nrf2 activation. J Biol Chem 280: 31768-31775, 2005.

39. McCarty MF: Versatile cytoprotective activity of lipoic acid may reflect its ability to activate signalling intermediates that trigger the heat-shock and phase II responses. Med Hypotheses 57: 313-317, 2001.

40. Suzuki YJ, Mizuno M, Tritschler HJ and Packer L: Redox regulation of NF-kappa B DNA binding activity by dihydrolipoate. Biochem Mol Biol Int 36: 241-246, 1995

41. Sen CK and Packer L: Antioxidant and redox regulation of gene transcription. FASEB J 10: 709-720, 1996.

42. Teichert J, Kern J, Tritschler HJ, Ulrich H and Preiss R: Investigations on the pharmacokinetics of alpha-lipoic acid in healthy volunteers. Int J Clin Pharmacol Ther 36: 625-628, 1998. 